\title{
Ein Blick hinter die Kulissen
}

\section{Matthias Scholer}

Online-Redaktor

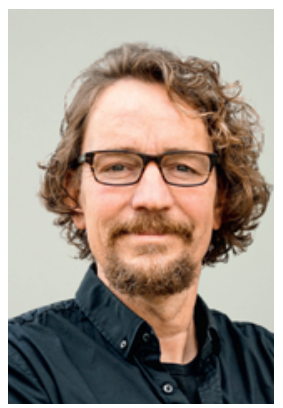

Pro Woche verlassen rund 38500 Printexemplare der Schweizerischen Ärztezeitung unser Haus. Werden diese anschliessend gelesen, oder nur durchgeblättert? Oder verschwinden sie sogar kaum beachtet im Poststapel? Anhaltspunkte dazu lieferte uns zuletzt eine 2010 durchgeführte Leserbefragung [1]. Im Vergleich mit solchen aufwendigen und teuren Studien haben es Onlineredaktoren einfacher.

Für uns analysiert Google das Verhalten der User auf Schritt und Tritt und das erst noch sekundengenau.

\section{Regelmässiger Puls}

Was wie ein EKG aussieht (vgl. Abb.1), ist in Tat und Wahrheit die Verlaufskurve der Sitzungen auf der Webseite saez.ch bzw. bullmed.ch. Der regelmässige Peak mit im Schnitt rund 1300 Besuchen fällt immer mit dem Versand des Newsletters zusammen. Danach sinkt das Interesse $a b$, um dann jeweils montags und dienstags erneut auf rund 500 Sitzungen pro Tag anzusteigen.

\section{Demographische Verteilung}

Nicht ganz überraschend ist die Altersverteilung der User. Etwas über die Hälfte liegen zwischen 25 und 45 Jahren, 9\% sogar erst zwischen 18 und 24 Jahren. Übrigens teilt sich die Leserschaft in rund 55\% männliche und $45 \%$ weibliche Besucherinnen auf, wobei letztere im Schnitt pro Sitzung mehr Seiten anklicken und länger auf der Webseite bleiben. Die demographischen Daten von Google Anayltics sind mit einer gewissen Unschärfe verbunden. Generell werden sie über Cookies und/oder Logins bei Googlediensten, welche ein User verwendet, gewonnen. Bei Rechnern in Unternehmen und Praxen können solche Daten in den wenigsten Fällen erhoben bzw. einem User zugeordnet werden.

\section{Regionale Verteilung}

Bei rund 68,5\% der User ist die Browsereinstellung deutsch und nur bei knapp 19\% französisch. Über die Gründe dafür lässt sich spekulieren.

Die Schweizerische Ärztezeitung wird aber auch im Ausland gelesen. Immerhin erfolgt rund ein Viertel der Webseiten-Besuche grösstenteils aus dem benachbarten Ausland.

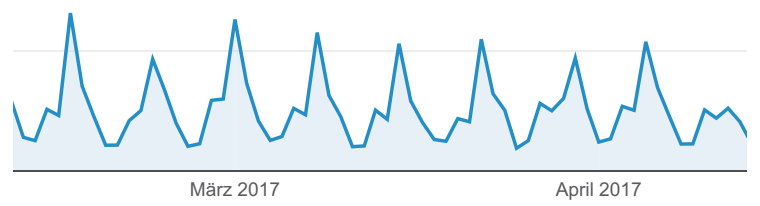

Abbildung 1: Zugriffe auf www.saez.ch bzw. www.bullmed.ch

\section{Vermehrt Zugriff von unterwegs}

Zurzeit nutzen rund 76\% die Angebote der SÄZ-Website von einem Desktop-Computer aus, ein Viertel von mobilen Geräten (rund 17,5\% über Mobiltelefone und rund 6,5\% über Tablets). Die mobile Nutzung nahm im Vergleich zur Vorjahresperiode ${ }^{1}$ um rund $55 \%$ zu. Deshalb hat sich der Schweizerische Ärzteverlag EMH als Betreiber der Website auch dazu entschlossen, unter anderem die «Mobile Responsiveness» der WebseitenInhalte an die neuen Bedürfnisse anzupassen [2].

\begin{tabular}{|c|c|c|}
\hline 1. $\square$ & Switzerland & $\mathbf{5 2 . 5 3 6}(73,38 \%)$ \\
\hline 2. $\equiv$ & Germany & $\mathbf{8 . 3 7 6}(11,70 \%)$ \\
\hline 3. $\|$ & France & $2.440(3,41 \%)$ \\
\hline 4. $\equiv$ & Austria & $\mathbf{1 . 1 8 1}(1,65 \%)$ \\
\hline 5. \|ा । & Italy & $791 \quad(1,10 \%)$ \\
\hline 6. 国 । & United States & $710(0,99 \%)$ \\
\hline 7. 장 & United Kingdom & $556(0,78 \%)$ \\
\hline
\end{tabular}

Abbildung 2: Die SÄZ findet auch im Ausland Beachtung.

Ersetzt das Onlineangebot bald die Printversion? Nein. Zurzeit sehen wir unseren Webauftritt als wertvolle Ergänzung zum Print, als praktisches Archiv für unsere Leserschaft und als aktuelle Plattform für Stelleninserate bzw. Veranstaltungshinweise. Doch auch wir müssen und wollen mit der Zeit gehen, weshalb wir einerseits vermehrt multimediale Inhalte auf der Webseite anbieten werden und andererseits unsere Präsenz in den Sozialen Medien aufbauen möchten.

Bildnachweise

Screenshots @ Google Analytics

\section{Referenzen}

1 Marty N. Die meistgelesenen Fachzeitschriften der Schweiz. Schweiz Med Forum. 2010;10(51-52):928-34.

2 Kesseli B. Vielfältig, schnell, flexibel. Schweiz Ärztezeitung. 2017;98(10):326. 